\title{
Production Logistics Visibility - Perspectives, Principles and Prospects
}

\author{
Ravi KALAIARASAN ${ }^{\mathrm{a}, \mathrm{b}, 1}$, Jan OLHAGER ${ }^{\mathrm{c}}$, \\ Magnus WIKTORSSON ${ }^{\mathrm{a}}$ and Yongkuk JEONG ${ }^{\mathrm{a}}$ \\ ${ }^{a}$ KTH Royal Institute of Technology, Sweden \\ ${ }^{\mathrm{b}}$ Scania $C V A B$, Sweden \\ ${ }^{\mathrm{c}}$ Lund University, Sweden
}

\begin{abstract}
Globalisation, competitive markets and increasing sustainability requirements are demanding companies to focus on visibility to improve their supply chains and ultimately their businesses. This paper aims to identify perspectives, principles and prospects of production logistics visibility (PLV). The study is based on a literature review of articles presenting definitions, development trends and the future role of PLV. It is concluded that visibility is generally defined by availability, quality, accessibility and usefulness of information. PLV could refer to the extent to which actors within the production systems have access to timely and accurate information considered useful to their operations. According to the findings, antecedents of PLV include digitalisation, IoT and connectivity. These steps are required to turn data into meaningful information that can be used for decision making in production and logistics setting to improve operational and business performance. Furthermore, to fully benefit from PLV, there has to be an integration of external and internal perspectives. Concluding, the paper defines future research efforts including four lines of exploration and development: (1) Intra-site visibility for material management including dynamic synchronisation, takt and resource planning. (2) Supply-oriented visibility for dynamic status and prediction of supply network status. These two initial lines of enquiry should include the perspectives of stakeholders, parameter, enabling technologies and potential impact. (3) A synthesised framework for Production Logistics Visibility, relying on utilizing antecedents and enabling multi-criteria decision in production logistics based on visibility, where performance in terms of efficiency, sustainability and flexibility is ensured. (4) To specifically detail and exploit the potential in production logistics visibility in the aspect of environmental sustainability and closed material and product loops.
\end{abstract}

Keywords. Digitalization, Production logistics, Supply Chain, Visibility.

\section{Introduction}

A more global supply base, operations and markets, as well as digitalization and sustainability requirements, put the integration of manufacturing and logistics as one key element for the transition of future European manufacturing industries [1]. It is of utmost importance to developed knowledge for manufacturing industries towards sustainable production aiming at "doing more and better with less", by reducing resource use,

\footnotetext{
${ }^{1}$ Corresponding Author. ravi.kalaiarasan@scania.com
} 
degradation and pollution within the value network. This implies the need to focus on operating on value network level, further integrating the activities of manufacturing and logistics.

In this value network perspective, dynamic capabilities will be a key competitive advantage. As intersection of manufacturing and logistics, production logistics (PL) is critical for this change, where PL concerns the resources, planning and control of material and information flow within the production and logistics system. For Swedish manufacturing operations, emerging from this period of transition as healthy, it depends in large part on how their production logistics adapt to dynamically changing environments. Higher speed and efficiency will help, but will not be sufficient. PL needs fact-based intelligence to predict which future scenarios are most likely to occur - and the flexibility to get repositioned before they do.

Based on the foundations of digitalisation and connectivity, visibility is considered a key element for competitiveness among industrial leaders [2]. Visibility means in this case having the information you need at the time you need it. The information should furthermore be current, accurate, complete and usefully formatted. The visibility is considered as a first step towards digital maturity and dynamic capability. Sanders and Swink [2] further emphasise that leading industries focus on develop visibility that supports in avoiding uncertainties and/or offer the greatest potential, rather than exploiting the types of visibility that is easy available. Visibility has been of increasing interest in supply chain management, with efforts upstream and downstream on standards and technologies for secure data capture, storage and transmission. However, given the key role of production logistics as the interface of manufacturing and logistics, and the importance of exploring the visibility aspects, a study on production logistics visibility is motivated.

Hence, the objective of this paper is to analyse and discuss the specific characteristics of visibility within PL, in order to enable dynamic and sustainability capabilities. The study is based on a literature review of articles presenting definitions, development trends and the future role of production logistics visibility (PLV).

\section{Related literature}

Based on a brief literature review, we define production logistics visibility and discuss trends and challenges. Citation pearl growth [3] was used as search strategy for finding relevant literature, i.e. starting from a few sources to identify suitable terms in those documents that could be used as keywords for further search in Scopus.

\subsection{Defining production logistics visibility}

The literature provides numerous suggestions for defining production logistics visibility, relating it to the term supply chain visibility. But let us first quickly review the three parts of "production logistics visibility", i.e. production, logistics, and visibility.

Production can be defined as "the conversion of inputs into finished products" [4]. A related concept is manufacturing, which by APICS is defined as "a series of interrelated activities and operations involving the design, material selection, planning, production, quality assurance, management, and marketing of discrete consumer and durable goods" [4]. This reflects the US perception where manufacturing is broader than production. This perspective is also represented in e.g. the definitions on manufacturing 
and production by CIRP [5]. However, in other parts of the world the relationship is reversed, such that manufacturing is considered as the activity of creating the form of the product, while production includes a wider set of activities and operations. For example, services can be produced but not manufactured.

Logistics can be defined as "the subset of supply chain management that controls the forward and reverse movement, handling, and storage of goods between origin and distribution points", which includes "obtaining, producing, and distributing material and products in the proper place and in proper quantities" [4]. In the original military sense, logistics is concerned with the movement of goods and personnel.

Visibility means having the information you need at the time you need it, and can be defined as "the ability to view important information throughout a facility or supply chain no matter where in the facility or supply chain the information is located" [4]. Key aspects of visibility are availability (currency) and quality (accuracy, usefulness) of information [6], [7], [8]. Sanders and Swink [2] emphasize that "good information comes from data that are current, accurate, complete and usefully formatted". For example, an Andon system provides visibility of current floor status through on-line electronic boards in a standardized format that is easily accessible and interpreted.

Many authors have proposed definitions of supply chain visibility (which is a term that is more commonly used in the literature than production logistics visibility). First, we provide some examples of definitions from previous research, before we provide our definition of PLV.

According to APICS [4], supply chain visibility (SCV) is "the ability of supply chain partners to access demand and production information from trading partners". Related literature reveal that there are a range of definitions available for SCV. For instance, one definition is "traceability and transparency of supply chain process" [9]. This indicates that one important aspect of SCV is to be able to track transparent information both down and upstream in the supply chain.

Others accentuate the importance of having access to and sharing of relevant information when defining SCV. For example Kaipia and Hartiala [10] provide a definition of SCV as the sharing of all relevant and meaningful information between SC partners and also over echelons in the chain. It is regarded that one of the attributes of SCV is to provide opportunity for stakeholders to access relevant information [11], [12].

Management of flows and the supply chain is mentioned when defining SCV. One example is the management of flows of products, services and information [13]. Management based on SCV concerns both the upstream and downstream flow [14].

Authors also emphasize the importance of quality when defining SCV. Chan [15] defines SCV as the quality of information transferred between suppliers, manufacturers, distributors and customers. Also, Williams et al. [7] describe SCV as having access to information of high quality describing various factors of demand and supply.

When defining SCV authors also highlight that it should result in improvements of processes, flows and operations. Increased effectiveness of the supply chain due to sharing of information is mentioned when defining SCV [17].

Based on the available literature and the conceptual descriptions of supply chain visibility, we propose that PLV can be defined as the following:

"The extent to which actors within the production system have visual access to the timely and accurate demand and supply information that they consider to be key or useful to their operations".

This definition is in line with definitions by Barratt and Barratt [6], and Barratt and Oke [18]. Further, PLV can also be considered as a process that can be measured in terms 
of its effectiveness, in line with [19]. The definition further indicates that the key viewpoint is that from an actor within a production system having visible access to internal information regarding supply or demand within the production system as well as external information up- or downstream, depending on their need.

\subsection{Perspectives on enablers and drivers for visibility}

To address the perspectives of visibility, it is relevant to explore the enabling solutions proposed and developed for improved value-creating information sharing, as well as the drivers motivating the increasing interest on visibility. These enabling solutions include Internet of Things (IoT) - solutions, visualization and prediction, supporting decision making processes [20]. The drivers for increased visualisation includes regulatory, market and competition perspectives.

\section{Digitalisation}

One of the more prominent trends is digitalisation to increase and address the challenges of visibility. Sanders and Swink [2] define digital supply chain as a digital supply chain utilizing 'digital' "technologies to plan and execute transactions, communications and actions". Further, they mention that notions such as automation and artificial intelligence are embedded with this definition [2]. The goal for supply chain relationships is to improve traceability and transparency in all parts of the value network, through technology that enables increased transparency in working methods, fulfilment of requirements and performance [21].

\section{IoT}

Improved visibility using IoT is expected the influence the way companies work with their supply chains [20]. Pundir et al. further mention that the "Future will be a complete integration of IoT technology with new upcoming technologies like blockchain" to ensure visibility across the supply chain [20]. Ellis et al. [22] state that companies have built solutions for supply chain visibility "leveraging IoT technology" in order to achieve visibility of and connectivity of their "products and processes".

\section{Connectivity}

Collaboration between companies with the intention of mutual benefit is a challenge for attaining visibility across the supply chain. Companies have to display willingness to share information and have an optimistic behaviour. For instance, improved sustainability will demand focus on visibility, which again will require firms to exchange information [23]. Trust can be established by the exchange of information upstream and downstream in the supply chain. This will also support to strengthen the relationships between the partners [24].

\section{Visibility for decision making}

To benefit from visibility it is important to ensure that information is available in the right format and obtainable when needed (in line with [2]). The interview conducted by Sanders and Swink [2] revealed that many supply chain managers stated that data was available. However, the data was not converted into information and presented to the right decision maker at the right time. Similar result was the outcome of interviews and surveys conducted by Goh et al. [25] within the pharmaceutical sector in Singapore. The companies "highlighted the importance of SCV for decision making because they are 
decision makers and they need timely information to make a decision effectively and efficiently" [25].

\section{Competitive edge - performance}

Visibility is considered as an enabler for competitive edge. The case study performed by Caridi et al. [26] at a company operating within the aerospace industry implies that the transparent relationship and frequent communications with supply network is vital for competitiveness. Lee et al [23] mention that a supply chain with "superior informationsharing mechanisms among SC partners will be able to outperform competing supply chains with less effective information-sharing mechanisms". Kim et al. [24] state that visibility is key to determine the competitiveness of a supply chain. Furthermore, visibility can be used to determine and anticipate changes in supplier, customer and competitor markets [27].

\section{Conceptual framework - principles and prospects}

Visibility within the production logistics is a key instrument for future dynamic development, for resource efficiency, sustainability, and competitiveness. External and internal information need to be transparent for making decisions on planning, control and development of production logistics. A new research project on PLV called LOVIS will address these issues and challenges.

PLV concerns both internal and external production and material flows. LOVIS will explore and demonstrate both perspectives: (1) intra-site real-time visualisation perspective for material management including dynamic synchronisation, takt and resource planning, and (2) a supply visibility system for dynamic status and prediction of supply network status. Figure 1 illustrates the fundamental logic when developing production logistics visibility.

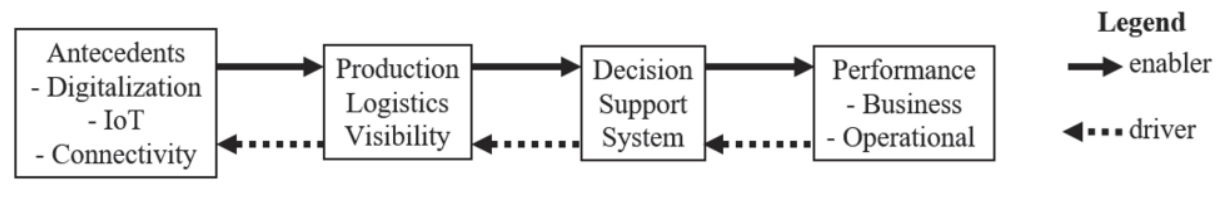

Figure 1. Implication logic for production logistics visibility, including the perspectives (Solid arrows depict enablers, and dashed arrows depict drivers).

Implication logic for PLV visibility is presented in Figure 1 above. The antecedents to PLV includes the utilization of new technologies such as digitalization, IoT and connectivity between organizations. These steps are required to turn data into meaningful information that can be used for decision making in production and logistics setting to improve operational and business performance. The implication logic functions from left to right. However, it can be considered that the demand/requirement logic (the drivers) occurs from right to left. This indicates a dynamic flow ensuring possibilities for continuous improvements. 


\begin{tabular}{|c|c|c|c|c|}
\hline & \multicolumn{2}{|c|}{ Inbound } & \multicolumn{2}{|c|}{ Outbound } \\
\hline & Suppliers & Production & Distribution & Customer \\
\hline Performance & $\begin{array}{l}\text { Flow efficiency } \\
\text { Responsiveness }\end{array}$ & $\begin{array}{l}\text { Resource efficiency } \\
\text { Responsiveness }\end{array}$ & $\begin{array}{l}\text { Resource efficiency } \\
\text { Responsiveness }\end{array}$ & $\begin{array}{l}\text { Quality, Delivery, } \\
\text { Cost, Service }\end{array}$ \\
\hline Decision support & $\begin{array}{l}\text { Quality } \\
\text { Lead time } \\
\text { Cost }\end{array}$ & $\begin{array}{l}\text { Quality, Lead time } \\
\text { Bottlenecks } \\
\text { Resource utilization }\end{array}$ & $\begin{array}{l}\text { Lead time } \\
\text { Resource utilization } \\
\text { Forecasting }\end{array}$ & Demand \\
\hline Visibility & $\begin{array}{l}\text { Supplier dashboard } \\
\text { Track \& trace } \\
\text { Shortages }\end{array}$ & $\begin{array}{l}\text { Production dashboard } \\
\text { Track \& trace } \\
\text { Root causing }\end{array}$ & $\begin{array}{l}\text { Distribution dashboard, } \\
\text { Track \& trace } \\
\text { Product availability }\end{array}$ & $\begin{array}{l}\text { Customer dashboard } \\
\text { Track \& trace }\end{array}$ \\
\hline $\begin{array}{r}\text { Digitalization } \\
10 T \\
\text { Connectivity }\end{array}$ & Blockchain & $\begin{array}{c}\text { Robot Process } \\
\text { Automation (RPA) }\end{array}$ & $\begin{array}{l}\text { Robot Process } \\
\text { Automation (RPA) }\end{array}$ & Blockchain \\
\hline
\end{tabular}

Figure 2. Principles and prospects for PLV

Possible principles and prospects for PLV across the supply chain are presented in Figure 2. The implication logic, explained in Figure 1, is applicable for each area; suppliers, production, distribution and customers. Figure 2 also indicates that there is a need to focus on technology across the supply chain to fully benefit from PLV. Furthermore, areas where PLV can enable decision support to ultimately measure and improve performance areas are presented. Figure 2 entails that visibility have an impact on both the inbound and outbound processes. The visibility within each of these areas are interrelated and influence the decisions and performances.

\section{Performance}

Utilization of visibility can improve the performance across the supply chain. The results obtained by Lee et al. [23] showed than an increase of visibility in inter- organizationalsystem leads to increase of performance. Figure 2 implies that visibility does not only support decision making within an organisation, but can potentially improve the collaborative decision making across the supply chain (in line with [20]). Figure 2 further indicates that PLV can impact operations and development of the supply chain strategy [28]. For instance, the information available can be utilized to run, control and improve operations [28], [29].

Increased level of environmental regulations imposed by governments and unions globally are leading companies to increase their PLV to prove their compliance. Many internationally recognized companies have suffered reputational and financial loss due to being held responsible for supplier misconduct [16]. Also, possible misconduct of sustainability is not always reflected in the product [30]. Pundir et al. [20] mention that specific "items require affirmation of ecological variables"

\section{Decision support}

The decision support system has to be capable of providing the decision maker with timely and accurate information, and visualizing these in a proper format to guide the decision maker towards improved performance. This includes identifying and managing 
risks in the supply chain in areas such as supplier misconduct and sustainability related topics. Also, Busse et al. [31] mention that sustainability related conditions upstream in the supply chain can cause issues for buying firms. An increased visibility can support decision makers to identify and prevent similar issues. Figure 2 implies that decision points regarding lead time, quality and demand can potentially be found across the supply chain. The decisions can support different task such for the user. Examples of tasks include visualizing, diagnosing, predicting, prescribing and cognifying [2].

\section{Visibility}

One way to perceive visibility is through a dashboard displaying information. It is essential to connect stakeholders in real time and to ensure that dashboard have data models and applications integrated [32]. Figure 2 illustrates the possibility and potential need to have dashboards across the supply chain. In the dashboard solutions it is essential to cover both a process-based perspective focusing on the efficient value-adding flow throughout the supply network, as well as a resource-based perspective focusing on the utilisation of production resources such as equipment, material, energy, machinery and personnel [33]. IT can be standardized or customized depending on the needs from users and stakeholders. The dashboard could be used to show information related to visibility dimensions. Sanders and Swink [2] presents dimensions that include demand, inventory, processes/capacity, assets, markets, pipeline threats, disruptions and KPIs.

\section{Digitalization, IoT and connectivity}

One of the key factors to attain PLV across the supply chain is the usage of advancements of information systems [23]. Technology is vital to provide visibility of already existing data but also to add new visibility using for instance digitalization and connectivity. Figure 2 implies that visibility can improve the inbound processes by improving connectivity between for example suppliers and production units. This can for example result in improved performance of material management [28]. Also the study by Caridi et al [26] in the aerospace industry showed that the availability of spare parts had a direct impact on production lead time. Technologies such as blockchain can be utilized to enable real time visibility across or within selected areas. Shell et al. [21] present a hybrid blockchain solution to support fulfilment phase by providing real-time visibility in the area of physical distribution. IoT can be considered as an enabler for digitalisation and connectivity. Pundir et al. [20] describe a case where "IoT-enabled use case for the last mile" creating "optimized collection from mail boxes". Digitalisation is key to provide real time, accurate, complete and useful data. Also, artificial intelligence in combination with automation can support processing the data [2].

\section{Discussion and concluding remarks}

\subsection{Drivers for $P L V$}

This paper strengthens the view that increased globalisation and more complex supply networks are demanding a higher level of functionality in the end-to-end visibility [20]. Further, this study reveals that environmental factors are also driving the need for companies to focus on PLV. This indicates that there is a push and pull demand for PLV. For example, the study presented by Caridi et al. [26] reveal that companies are leaning towards PLV with the aim to establish competitive edge. Furthermore, results presented 
by Srinivasan and Swink [27] implies that visibility can be used for competitive intelligent by continuously gathering and evaluating data. At the same, companies are focusing on visibility from suppliers to avoid damages caused supplier misconduct [16]. This points out that customers, besides the delivery of a product and/or service, are also demanding transparency of the delivery and related information. This implies that more companies will be required to both demand and deliver information using PLV.

\subsection{Perspectives on PLV}

Many agree that one perspective regarding PLV is that technology is and will continue to be a key enabler. For instance digitalization, connectivity, IoT and blockchain are considered to play a key role for the future development of PLV [20], [21], [23], [26]. However, this study implies that to fully implement PLV, several technology solutions have to be utilized and possible coexist. Furthermore, the study show that many of the PLV enabling solutions can complement each other (in line with [20]). There is also a perspective mentioning that PLV should enable and support decisions for key stakeholders and decision makers [2], [16], [25]. This study shows that different types of dashboards such as supplier and production dashboard can be implemented to display accessible and useful data in real time. However, except for dashboard, this study did not reveal more platforms to display visibility in a user-friendly way.

One observation is how much artificial intelligence in combination with automation can impact the decisions. One potential outcome is that artificial intelligence and automation together can make decisions for certain tasks. However, in other areas it is likely that decision support and scenarios with recommended actions are presented for the stakeholders and are left for their final confirmations and approvals. This implies that decisions of certain levels and complexities can be automated.

\subsection{Principles and Prospects}

The principles and prospects found in this study indicate that PLV demands collaboration across the supply chain to be fully implemented and further improve business performance from operational and strategical point of view [23], [24], [28], [29]. One challenge to attain this is the synchronization that need to occur on several levels. For instance, these synchronizations include customer vs. supplier and process vs. relationship [23]. This implies that PLV require focus on technology, processes and relationships. There need to be an alignment between these areas in order to have PLV. It important to address the need of integration within and outside a company. For example, internal visibility will require an alignment of technology, processes and relationships within a company such as a production unit. Similarly, external visibility will require alignment with suppliers and others partners in the supply chain. This entails that there has to be a combined view of internal and external visibility to implement PLV.

\subsection{Implications and further research}

Visibility within the Production Logistics is a key instrument in this future dynamic development, for resource efficiency, sustainability and competitiveness. External and internal information need to be transparent to development, planning and control of the production logistics, enabling a smart asset management including processes, technology 
and organizational issues. Based on the literature review and discussion, we provide a few suggestions for further research, which also will be explored in the LOVIS project:

- To further explore intra-site visibility for material management including dynamic synchronisation, takt and resource planning. This line of enquiry should include the perspectives of: (1) stakeholders, their decision points and decision criteria (2) parameters to consider when designing and operating the production logistics system, (3) enabling technologies for visibility and how these are aligned with e.g. security, power structures, legal and autonomy and (4) the intra-site visibility's potential impact on total resource efficiency.

- To further explore supply-oriented visibility for dynamic status and prediction of supply network status. This line of enquiry should also include the perspectives of stakeholders, parameter, enabling technologies and potential impact, as above.

- To integrate the two above perspectives into a synthesised framework for Production Logistics Visibility. The framework should rely on exploring and utilizing the antecedents and enable multi-criteria decision and development of production logistics based on visibility, where performance in terms of efficiency, sustainability and flexibility is ensured.

- To specifically detail the potential and exploitation of production logistics visibility in the aspect of environmental sustainability and closed material and product loops.

\section{Acknowledgement}

We gratefully acknowledge the funding from Produktion2030 and Vinnova for this research, as part of the research project Production Logistic Visibility (LOVIS).

\section{References}

[1] ALICE. Global supply network coordination and collaboration. The European Technology Platform ALICE Research and Innovation Roadmap. Accessed at ww.etp-logistics.eu. 2018.

[2] N. Sanders and M. Swink, Digital supply chain transformation: Visualizing the possibilities, Supply Chain Management Review, January 2019, pp. 30-41.

[3] J. Rowley, and F Slack, Conducting a literature review, Management Research News, vol. 27 no. 6 , 2004, pp. 31-39.

[4] APICS, APICS Dictionary, $16^{\text {th }}$ Ed., 2019.

[5] CIRP, Nomenclature and Definitions for Manufacturing Systems (English Language Version). In: Annals of the CIRP. 39 (2): $735-742$.

[6] M. Baratt and R. Baratt, Exploring internal and external supply chain linkages: evidence from the field, Journal of Operations Management, vol. 29 no.5, 2011, pp. 514-528.

[7] B.D. Williams, J. Roh, T. Tokar and M. Swink, Leveraging supply chain visibility for responsiveness: the moderating role of internal integration, Journal of Operations Management, vol. 31 no. 7-8, 2013, pp.543-554.

[8] H. Zhou, and W.C. Jr. Benton, Supply chain practice and information sharing, Journal of Operations Management, vol. 25 no. 6, 2007, pp. 1348-1365.

[9] Y.K. Tse and H.K. Tan, Managing product quality risk and visibility in multi-layer supply chain, International Journal of Production Economics, vol. 139 no. 1, 2012, pp. 49-57.

[10] R. Kaipia and H. Hartiala, Information-sharing in supply chains: five proposals on how to proceed, International Journal of Logistics Management, vol. 17 no. 3, 2006, pp. 377-393. 
[11] R. Klueber and R. O'Keefe, Defining and assessing requisite supply chain visibility in regulated industries, Journal of Enterprise Information Management, vol. 26 no. 3, 2013, pp.295-315.

[12] R. Narashiman, S.W. Kim and K.C. Tan, An empirical investigation of supply chain strategy typologies and relationships to performance, International Journal of Production Research, vol. 46 no. 18, 2006, pp. 5231-5259.

[13] U. Balasubramaniam, M. Diab, M. Mabry, K. Moore, D. Nghe and N. Tunstall, Information visibility non differentiated products, Production and Inventory Management Journal, vol. 43 no. 1/2, 2002, pp. 69-88.

[14] P.A. Barlett, D.M. Julien and T.S. Baines, Improving supply chain performance through improved visibility, International Journal of Logistics Management, vol. 18 no 2, 2007, pp. 294-313.

[15] F.T.S. Chan, Performance measurement in a supply chain, International Journal of Advanced Manufacturing Technology, vol. 21 no 7, 2003, pp. 534-548.

[16] R. Bregman, D.X. Peng and W. Chin, The effect of controversial global sourcing practices on ethical judgements and intentions of US consumers, Journal of Operations Management, vol. 36, 2015, pp. 229-243.

[17] P. Jonsson and S.A. Mattson, The value of sharing planning information in supply chains, International Journal of Physical Distribution \& Logistics Management, vol. 43 no. 4, 2013, pp. 282-299.

[18] M. Barratt and A. Oke, Antecedents of supply chain visibility in retail supply chains: a resource-based theory perspective, Journal of operations Management, vol. 25 no. 6, 2007, pp. 1217-1233.

[19] J.S. McIntire, Supply Chain Visibility: From Theory to Practice, 2014, Gower Publishing, Surrey.

[20] A. Pundir, D. Jadhav and L. Ganapathy, Improving supply chain visibility using iot - internet of things, In: 9th IEEE Annual Computing and Communication Workshop and Conference, At University of Nevada, Las Vegas, USA, 2019.

[21] Z.L. Shell, H. Wu, B. King, Z.B. Miled, J. Wassick and J. Tazelaar, A Hybrid Blockchain Ledger for Supply Chain Visibility, In: $17^{\text {th }}$ International Symposium on Parallel and Distributed Computing, 2018.

[22] S. Ellis, H. D. Morris and J. Santagate, IoT-Enabled analytic applications revolutionize supply chain planning and execution, November, 2015.

[23] H. Lee, M.S. Kim and K.K. Kim, Interorganizational information systems visibility and supply chain performance, International Journal of Information Management, vol. 34, 2014, pp. 285-295.

[24] K.K. Kim, S. Ryoo and M.D. Jung, Interorganizational information systems visibility in buyer-supplier relationshps: The case of telecommunication equipment component manufacturing industry, Omega, vol. 3, 2011, pp. 667-676.

[25] M. Goh, .R De. Souza, AN. Zhang, W. He and P.S. Tan, Supply chain visibility: A decision making perspective, Industrial Electronics and Applications (ICIEA), 2009.

[26] M. Caridi, A. Moretto, A. Perego and A. Tumino, The benefits of supply chain visibility: A value assessment model, International Journal of Production Economics, vol. 151, 2014, pp. 1-19.

[27] R. Srinivasan and M. Swink, An investigation of visibility and flexibility as complements to supply chain analytics: An organizational information processing theory perspective, Production and Operations Management, vol. 27 no. 10, 2018, pp. 1849-1867.

[28] S. Somapa, M. Cools and W. Dullaert, Characterizing supply chain visibility - a literature review, International Journal of Logistics Management, vol. 29 no. 1, 2017, pp.308-339.

[29] C. Swift, V.D.R. Guide and S. Muthulingam, Does supply chain visibility affect operating performance? - Evidence from conflict minerals disclosures, Journal of Operations Management, vol. 5 no. 5, 2019, 406-429.

[30] H. Hofmann, C. Busse, C. Bode and M. Henks, Sustainability-related supply chain risks: conceptualization and management, Business Strategy and the Environment, vol. 23 no.3, 2014, pp. 160172.

[31] C. Busse, M.C. Schelper, J. Weilenmann and S.M. Wagner, Extending the supply chain visibility boundry, Utilizing stakeholders for identifying supply chain sustainability risks, International Journal of Physical Distribution \& Logistics Management, vol. 47 no. 1, 2017, pp. 18-40.

[32] C. Atzl, J. Scholz, B. Vockner, M. Mittböck and L. Knoth. Role-tailored map dashboards - A new approach for enhancing the forest- based supply chain, International Journal of Geo-Information, vol. 8 no. 1,2019 , pp. 41 -.

[33] G. Johansson, E. Sundin and M. Wiktorsson. Sustainable Manufacturing. Studentlitteratur. 2019. p.7273. 